\title{
Health-related quality of life and its predictors in Korean patients with myocardial infarction in the acute phase
}

Authors:

Kyoungrim Kang, PhD, MSN, BSN, RN

Assistant Professor, Pusan National University, Busan, S. Korea

E-mail: krkang@pusan.ac.kr

Phone: +82 (0)51 5108346

\#416, 49, Busandaehak-ro, Mulgeum-eup, Yangsan-si, Gyeongsangnam-do, 50612, Republic of Korea

Leila Gholizadeh, $\mathrm{PhD}, \mathrm{RN}, \mathrm{MSc}$, BSc

Lecturer, University of Technology Sydney, NSW, Australia

Email: Leila.Gholizadeh@uts.edu.au

Phone: +61295144814

Address: Lv.7, 235 Jones St, Ultimo NSW 2007, Australia

Hae-Ra Han, PhD, RN, MSN, BSN, FAAN

Professor, Johns Hopkins University, Baltimore, MD, USA

Email: hhan3@jhu.edu

Phone: (410) 614-2669

Address: 525 N. Wolfe St., Room 526 Baltimore, MD 21205

* The corresponding author: Kyoungrim Kang

Postal address: \#416, College of Nursing, Pusan National University,

49, Busandaehak-ro, Mulgeum-eup, Yangsan-si, Gyeongsangnam-do, 50612, Republic of Korea

Phone: +82 (0)51 510 8346, Fax: +82 (0)51 510 8308, E-mail address: krkang@ pusan.ac.kr

This article is based on a part of the first author's doctoral thesis from University of Technology Sydney.

Funding sources: All authors have no funding source to declare.

Conflict of Interest: The authors declare that they have no conflict of interests.

Authorship declaration: No conflicting interests have been identified by any of the authors.

Informed consent: Informed consent was obtained from all individual participants included in the study.

Ethical approval: All procedures performed in studies involving human participants were in accordance with the ethical standards of the institutional and/or national research committee and with the 1964 Helsinki declaration and its later amendments or comparable ethical standards.

Running head: HRQOL AND PREDICTORS IN THE ACUTE PHASE

Acknowledgement: Not applicable.

Bio: Kyoungrim Kang, PhD, MSN, BSN, RN, is an assistant professor at the College of Nursing, Pusan National University. Leila Gholizadeh, PhD, RN, MSc, BSc, is a lecturer at the Faculty of Health, University of Technology Sydney. Hae-Ra Han, PhD, RN, MSN, BSN, FAAN, is a Professor at the School of Nursing, Johns Hopkins University. 


\title{
Health-related quality of life and its predictors in Korean patients with myocardial infarction in the acute phase
}

\begin{abstract}
This study aims to investigate health-related quality of life (HRQoL) of Korean patients in the acute phase of myocardial infarction (MI) and correlates of this important patient outcome. A total of 150 patients with recent MI were recruited. The Korean version of the MacNew Quality of Life after Myocardial Infarction Questionnaire was used to assess their HRQoL. Demographic, behavioural and disease-related factors were also assessed and the Depression, Anxiety and Stress Scale (DASS 21) was used for psychological well-being. Participants who had a higher education level and better financial status had better HRQoL. Diabetes, history of stroke, other heart disease and a higher score of the DASS 21 were adversely associated with HRQoL. The findings of this study help identify risk factors that are related to lower HRQoL after MI. Early psychological and financial support may help reduce the impact of MI on patients' overall health and quality of life.
\end{abstract}

Keywords: Cardiovascular; factors; health-related quality of life; myocardial infarction; outcomes. 


\section{INTRODUCTION}

Cardiovascular disease (CVD) remains the number one killer of both men and women worldwide. Similar to international trends, CVD is a serious health concern in Korea. As the second leading cause of death in the country, CVD mortality has steadily increased since 2004 (Statistics Korea et al., 2018). Among CVD patients, those who experience myocardial infarction (MI) are at higher risk of subsequent physical consequences such as ventricular arrhythmias, reduced left ventricular function (Schmidt et al., 2016), and adverse psychological reactions (Xu et al., 2017). The physiological and psychological impact of MI, often with sudden onset and hospitalisation, negatively affect the overall health and health-related quality of life (HRQoL) of patients at the acute stage of post-MI (Wenru Wang et al., 2016).

The American Heart Association recommends HRQoL to be routinely assessed as a part of health status evaluation among patients with CVD (Benjamin et al., 2019). HRQoL is a subjective patient-reported outcome, presenting comprehensive indication of patients' health status and the impact of a life threatening event such as MI on their overall health and wellbeing, leading to a better understanding of their experience and recovery from MI (Lidell et al., 2015). This multidimensional concept can be useful for predicting future cardiac events, rehospitalisation, and mortality among MI patients, and help inform treatment decisions (Benjamin et al., 2019). The impact of the illness on HRQoL may be particularly evident in the early stages of MI, when patients are admitted to the cardiovascular centre shortly after MI. Those who are hospitalised less than a week following MI had significantly lower HRQoL than at the three-month follow-up (Kang, Gholizadeh, Han, \& Inglis, 2018).

There were many studies of correlates or predictors of HRQoL in patients with MI from various countries, yet the results were inconsistent throughout the variables. For instance, in a study, 
older age and being male predicted higher HRQoL (Arnold et al., 2013), whereas another study found younger age and female gender were related to better HRQoL (Oginska-Bulik, 2014).

Psychosocial distress, such as depression and anxiety, is more likely to appear in patients after MI than in the general population. This distress worsens cardiovascular morbidity and mortality, and negatively influences prognosis of MI (Wenru Wang et al., 2016), but the influence of psychosocial distress on HRQoL differs from stages of post-MI (Kang, Gholizadeh, Inglis, \& Han, 2017).

Identifying factors influencing HRQoL can be helpful in detecting vulnerable patients who may have lower HRQoL in the early stages. Based on predictors of HRQoL, developing strategies to reduce the impact of MI on patient experience and health status may be essential for post-MI care (Hawkes et al., 2013). However, the literature is scarce in relation to Korean patients' HRQoL and its predictors, particularly at the early stage of recovery from MI. This study aims to investigate HRQoL of Korean patients with MI in the acute phase and identify its predictors in this population.

\section{METHODS}

\section{Design}

This study adopted a cross-sectional study design using questionnaires and medical records to assess participants' HRQoL and to identify its predictors among patients with MI in South Korea.

\section{Participants and setting}

The study was conducted at the cardiovascular centres of two major tertiary referral hospitals in the southern part of South Korea. Consecutive patients admitted to the cardiovascular centres were recruited from August 2015 to February 2016. They were asked to participate in the study if they: 1) were admitted to a cardiac department with a diagnosis of MI (either STEMI or 
NSTEMI); 2) were able to understand and speak Korean; 3) resided in South Korea; and 4) had the ability to understand the study and provide an informed consent. After confirmation that no patients admitted were colour blind, the patients' competence to sign the consent and complete the research questionnaires as well as their cognitive status were assessed using the following steps: 1) a nurse who was taking care of the patient confirmed that patient had the ability to properly consent; 2) all patients were asked to state their names at the time of screening; 3) each patient was asked to correctly identify the colour of one of three coloured papers. Patients were excluded if they had cognitive impairment or were participating in other interventional studies, which could influence their HRQoL at the time this study was being conducted.

Sample size was estimated before data collection, taking into account 15 variables assumed to affect HRQoL in patients with MI based on previous literature. The formula by Tabachnick and Fidell (the number of cases needed $>50+8 \times$ the number of independent variables) was used for sample size calculation (Pallant, 2016). The sample size expected was 170 participants. A total of 215 patients were screened for the study inclusion and exclusion criteria, of which 150 patients $(69.8 \%)$ were enrolled in this study. Participants completed the study questionnaires about one week after experience of MI. Sixty-five patients did not participate in the study due to being unconscious $(n=1)$, refusal due to poor health condition $(n=23)$, inadequate hearing $(n=17)$, declined without any reason $(n=19)$, or discharged before enrolment $(n=5)$. Patients who refused to participate in the study due to poor health condition mentioned reasons such as experiencing dyspnoea, pain at the site of intervention, severe tremor, or tiredness.

\section{Research instruments}

\section{Demographical, behavioural and disease-related profile}

A questionnaire was developed for the purpose of the study to collect information on demographical, behavioural and disease-related characteristics of the participants. For the 
selection of independent variables, previous articles on predictors of HRQoL exclusively in patients with MI were thoroughly reviewed, and the revised Wilson \& Cleary model for HRQoL (Ferrans, Zerwic, Wilbur, \& Larson, 2005) was adopted to provide additional guidance.

The questionnaire included questions about age, gender, marital status, level of education, current employment status, and perceived financial situation. Information on the health behaviour profile of the participants was also collected including their physical activity level prior to MI, smoking, alcohol consumption, and medical history. Three levels of physical activity were identified and included: 1) having 'at least 30 minutes moderate physical activity most or all days of the week'; 2) 'less than 30 minutes moderate physical activity less than 5 days in a week' ; or 3) 'not physically active'. Smoking status was assessed as being a current smoker, a previous smoker or a non-smoker. Participants were asked if they regularly consumed alcohol prior to their recent hospital admission. The disease-related profile was collected from the medical records of the participants after obtaining their consent and included: ST-elevation (NSTEMI/STEMI), history of hypertension, diabetes, stroke, other heart disease, previous MI and other comorbidities. These variables were selected based on the results of a thorough review of the literature on factors affecting HRQoL of MI patients.

Psychosocial profile: Depression, Anxiety, and Stress Scale (DASS 21)

Psychological distress including depression, anxiety and stress have been found to be important factors affecting HRQoL of patients with MI (Hosseini, Ghaemian, Mehdizadeh, \& Ashraf, 2014). Thus, the current study considered measuring and examining the impact of these variables on HRQoL of Korean patients, using the Depression, Anxiety, and Stress Scale (DASS 21). The DASS 21 is the short form of the DASS 42, consisting of 21 items with each scoring from 0 (never) to 3 (almost always) and the total score for this scale ranging from 0 to 63. Higher scores on the scale reflect worse psychosocial status (Lovibond, Lovibond, \& 
Psychology Foundation of Australia, 1995). DASS 21 was well-validated and has been widely used in Western and Asian countries, including the Korean version of the tool (Cha, 2014). The total DASS 21 score was used and the alpha coefficient of this scale was 0.87 in the current study.

\section{Korean version of the MacNew}

The MacNew Quality of Life after Myocardial Infarction Questionnaire (MacNew) was used to assess HRQoL of MI patients in the present study (Dixon, Lim, \& Oldridge, 2002). The MacNew is one of the most popular disease-specific tools used to measure HRQoL of MI patients (Kang, Gholizadeh, Inglis, \& Han, 2016). Each item is scored on a seven-point Likert response format ranging from 1 to 7 . The total score of the MacNew is calculated using the mean scores of the 27 items with a range of 1 to 7 . A higher score on the scale indicates better HRQoL (Dixon et al., 2002).

The MacNew has proven to be a highly valid and reliable instrument. Its reliability has been established by a number of studies with Cronbach's alpha coefficients ranging from between 0.87 and 0.97 (Wrzesniewski \& Wlodarczyk, 2012). For the purpose of this study, the Korean version of the MacNew was employed following the procedure described by Guillemin, Bombardier \& Beaton (1993), and only the total score of the Korean MacNew was used for this study. The psychometric properties of this Korean version are presented in a separate study (Kang, Gholizadeh, Inglis, \& Han, 2018). The alpha coefficient for the 27 items of the Korean MacNew was 0.90 .

\section{Ethical considerations}

Ethics approvals were obtained from the Institutional Review Boards of both study sites (IRB no. H-1505-008-029 and IRB no. 05-2015-072) and the Human Research Ethics Committees of the university (HREC Approval No. 2015000254) prior to recruitment. Participants were 
informed that participation was voluntary and that they could withdraw from the study anytime without penalty. All ethical considerations met the international ethical standards of privacy and confidentiality. All enrolled patients signed the informed consent form prior to participation.

\section{Study procedure}

After the ethics approval of each Institutional Review Board was obtained, patients were recruited from two tertiary hospitals. In consultations with cardiologists and nurse managers at the participating hospitals, the study invitation letters were distributed to potential participants hospitalised in the cardiology units and they were invited to participate. The information letter outlined the aim of the research and the description of the process the researcher followed to collect data. Study participants who signed the consent form completed self-report questionnaires in a comfortable, private, and quiet place free from distractions. The questionnaires included DASS 21 and the Korean version of the MacNew as well as questions regarding demographic, behavioural, and disease-related factors. A student investigator monitored the condition or stress of the participants while they were answering questions. Clinical data of the participants were obtained from medical records.

\section{Statistical analyses}

SPSS for Windows 24.0 was used to analyse the data. We used descriptive statistics including means, standard deviations (SD), frequencies and percentages to summarise the sample characteristics. The normality of the MacNew score was assessed and found to have normal distribution. Regression analysis was used to identify variables that predict HRQoL. As a preliminary analysis, an independent t-test or one-way analysis of variance (ANOVA) was used to decide which variables had an association with HRQoL and which of them were put into the first step of the regression model. The presence of multicollinearity was checked by tolerance, by variance inflation factor (VIF) and by correlations between the independent variables. 
Values of tolerance were higher than 0.10 and values of VIF were less than 10 , indicating the absence of multicollinearity. In addition, Pearson correlation coefficients showed values of lower than 0.90, indicating no violation of multicollinearity (Pallant, 2016). Stepwise regression analysis was applied to identify predictors associated with HRQoL of patients with MI until the final model was determined. The variables were included in the first step of stepwise analysis if their $\mathrm{p}$ value was 0.05 or less. Refinement of the model was completed using stepwise regression analysis. The most insignificant variables were removed gradually at different steps. The level of significance of all statistical analyses implemented was set at $p<0.05$ and twotailed.

\section{RESULTS}

\section{Participant characteristics}

Table 1 shows the participants' demographic, behavioural, disease-related and psychosocial characteristics, as well as the breakdown of the MacNew scores according to these characteristics. The mean age of the participants was 64.63 years $(\mathrm{SD}=11.48)$ ranging between 21 and 86 years. The majority of the participants were over 55 years old ( $\mathrm{n}=120,80.0 \%)$, male $(\mathrm{n}=107,71.3 \%)$, and married $(\mathrm{n}=129,86.0 \%)$. More than half of the participants $(\mathrm{n}=85,56.6 \%)$ had an education level of high school or above, and $40 \%(n=60)$ were currently employed. A majority of participants self-evaluated their financial situation as "only fair" or "poor" $(\mathrm{n}=129$, $86.0 \%)$, and approximately half of them $(n=77,51.3 \%)$ were not physically active. One third of the participants $(n=50,33.3 \%)$ were current smokers and about $30 \%(n=43,28.7 \%)$ consumed alcohol. 59.3\% $(\mathrm{n}=89)$ of participants were diagnosed with non-ST-elevation MI (NSTEMI) and 40.7\% (n=61) ST-elevation MI (STEMI) patients. Half of the participants $(\mathrm{n}=75$, $50.0 \%)$ were diagnosed with hypertension and approximately one-third with diabetes $(n=47$, $31.3 \%)$. Several patients had a history of stroke $(n=8,5.3 \%)$ and 25 patients $(16.7 \%)$ had a 
history of other heart disease such as valve disease or heart failure. A history of previous heart attack was present in $24.7 \%$ of participants. More than a third $(n=58,38.7 \%)$ had other comorbidities, including kidney problems and thyroid illness. When HRQoL of MI patients in this study was assessed, the overall score of the MacNew among the 150 participants was 4.46 ( $\mathrm{SD}=0.83$ ), calculated by taking average scores over 27 items, and the average total score on the DASS 21 was 17.05 ( $\mathrm{SD}=9.26)$. A statistically significant Pearson $r$ correlation was found between the DASS 21 subscale and MacNew scores. Among the 17 factors presented in Table 1, two factors - ST-elevation and other comorbidities - were not related to HRQoL for this patient population. Thus, these were excluded from the regression model.

\section{Predictors of HRQoL}

Table 2 provides the bivariate relationships as intercorrelations among the independent variables, testing the multicollinearity of the variables used in the regression model. Initially, 15 variables were subjected to the stepwise regression analysis. Demographic factors included age, gender, marital status, the level of education, employment status and perceived financial status. Behavioural factors included physical activity, smoking and alcohol consumption. Disease-related factors included hypertension, diabetes, stroke, other heart disease and previous MI. Psychosocial factors included the DASS 21 total score. Six variables-financial status, physical activity, diabetes, history of stroke, history of other heart disease, and the DASS score-were significantly correlated with HRQoL among patients with MI. At the second step, the three most insignificant variables — age, gender and employment status — were eliminated. Among the demographic factors, level of education and financial status remained statistically significant and among the behavioural factors, only physical activity remained significant. Hypertension and previous MI were not significantly related to HRQoL, while the DASS 21 score showed a significant association with HRQoL. At the third step, after removing the most insignificant factors, which included marital status, alcohol consumption and previous MI, 
seven of the nine factors were significantly related to HRQoL. At the fourth step, these two insignificant factors were eliminated. The results of this step showed that physical activity did not have a statistically significant association with HRQoL among the participants. At the fifth step when physical activity was removed, the final model of the current study was attained and the $R^{2}$ was $0.486(F=22.570, p=0.000)$, indicating that this model explained $48.6 \%$ of the variance in HRQoL. Of the six demographic factors, only the level of education and patientperceived financial status predicted HRQoL of patients in the early days after MI. Participants who had a higher education level $(\beta=0.228, t=3.688, p=0.000)$ and who had perceived better financial status $(\beta=-0.169, t=-2.705, p=0.008)$ had better HRQoL. None of the three behavioural factors predicted HRQoL. Diabetes $(\beta=-0.210, t=-3.480, p=0.001)$, the personal history of stroke $(\beta=-0.150, t=-2.458, p=0.015)$ and history of other heart disease $(\beta=-0.193, t=-3.207$, $p=0.002$ ) were adversely associated with HRQoL. The total DASS 21 score steadily showed a statistically significant prediction for HRQoL throughout the steps $(\beta=-0.442, t=-7.224$, $p=0.000$ in the final model). A higher score of the DASS 21 was closely related to worse HRQoL among participants in the present study. The results of the stepwise regression analysis are shown in Table 3.

\section{DISCUSSION}

This study aimed to investigate HRQoL of patients in the acute phase of MI and to identify the factors that influence this patient outcome. The average age of the participants in this study was $64.63 \pm 11.48$ years, which was older than other studies recently conducted in other countries such as the US (Arnold et al., 2013), Iran (Hosseini et al., 2014), European countries (Lidell et al., 2015), Hungary (Rafael, Simon, Drótos, \& Balog, 2014), and China (Wenru Wang et al., 2016; W. Wang, Thompson, Ski, \& Liu, 2014); however, it was similar to the previous study among Korean post-MI patients, which reported the mean age of $64.95 \pm 10.91$ (Kim, Kim, \& Hwang, 2015). The present study paid close attention to the acute phase of recovery (less than 
a week since MI), while other cross-sectional studies focused on longer periods, for example, 13 days after MI (W. Wang et al., 2014), up to six months (Lidell et al., 2015), more than a 12month lapse from MI (Kim et al., 2015), 15 days to 30 months from diagnosis (Wenru Wang et al., 2016), and 2.81 \pm 2.62 years of the average time since MI (Oginska-Bulik, 2014).

The mean DASS 21 score for this study was 17.05 with a standard deviation of 9.26 . The fairly large standard deviation may be due to the fact that both the participants who had previously experienced MI and those who had the first onset of MI were included in this study. The American Heart Association reported that patients with recurrent acute coronary syndrome tended to have higher depression, anxiety, and stress than those with the first acute coronary syndrome (Benjamin et al., 2019).

The results of stepwise regression analysis revealed that education level, self-evaluated financial status, diabetes, history of stroke, history of other heart disease and total DASS 21 score were significant predictors related to HRQoL in the early days after MI. As shown in Table 3, the final model at the fifth step accounted for $48.6 \%$ of the variance explained. Among the variables significantly associated with HRQoL, the DASS 21 showed the highest standardised coefficient $(\beta=-0.442)$, indicating the strongest relationship with the patient's subjective health outcome. Next, the level of education $(\beta=0.228)$ and diabetes $(\beta=-0.210)$ had the second and third closest association, followed by other heart disease $(\beta=-0.193)$, financial status $(\beta=-0.169)$, and a history of stroke $(\beta=-0.150)$.

Education and self-evaluated financial status remained the only independent correlates of HRQoL among the demographic variables. These results are in line with previous similar studies that assessed HRQoL in patients with MI (Wrzesniewski \& Wlodarczyk, 2012). Health professionals may not be able to provide financial support to patients. Instead, educational programs can be provided to post-MI patients who perceive their economic situation as poor so 
as to elevate their HRQoL. People who have a higher level of education tend to be more aware of risk factors in their health and to derive more from health-related education than those who have a relatively lower education level. Also, longer education periods can lead to wider social resources, including financial and psychosocial support (Zimmerman \& Woolf, 2014). To elevate patients' education level, further long-term studies in this Korean population would be needed to improve HRQoL among MI patients.

Another demographic factor (financial status) showed a significantly positive relationship among MI patients in this study. It has been consistently found in previous literature that a higher income may predict higher HRQOL (Arnold et al., 2013; Kim et al., 2015; Wenru Wang et al., 2016). Similarly, in a study conducted in the general population in Korea, affluent participants reported better HRQoL (Hong, 2011). These results provides evidence for the important role of financial and social factors on an individual's health, as declared by the World Health Organisation (WHO, 2011). Health professionals can advise post-MI patients who have financial difficulties to contact social support services to discuss their financial situation.

Diabetes patients and those who had a history of stroke or other heart disease also showed worse HRQoL at the early stage of MI recovery. These are chronic conditions that can significantly affect various aspects of the patients' health and thus negatively affect the HRQoL outcome. Diabetes may increase the risk of cardiac morbidity and mortality (Uchmanowicz, LobozGrudzien, Jankowska-Polanska, \& Sokalski, 2013). It was previously found that diabetic patients with either NSTEMI or STEMI tended to have worse HRQoL than non-diabetic patients at the early stage of recovery (Uchmanowicz et al., 2013). Supporting patients to effectively manage their chronic disease is thus important for improving their health outcomes and HRQoL. 
In accordance with the results of the current study, it may be that MI patients with a history of other heart disease are more seriously influenced by a recent heart attack. This finding is supported by a previous literature regarding correlates of HRQoL of MI patients (Kang et al., 2017). Patients after MI persistently experience a life-threatening trajectory, an increased risk of depression and anxiety (Feng et al., 2016). Regular follow-ups encouraging patients to participate in cardiac rehabilitation programs are important to improve patient and disease outcomes. Cardiac rehabilitation programs usually contain exercise, education and regular visits to cardiologists and may help patients to more effectively manage their illness and recover HRQoL after MI (Anderson \& Taylor, 2014).

Previous studies have shown that depression, anxiety and stress are closely associated with HRQoL after MI (Arnold et al., 2013; Hosseini et al., 2014; Rafael et al., 2014). Consistent with the literature, the present study confirmed that the psychosocial profile, including depression, anxiety and stress, predicted lower HRQoL. These results suggest that health professionals should pay close attention to the psychosocial aspects of MI patients, particularly at the early stage. Individual optimisation and cultural adjustment may be important aspects in consideration of depression intervention (Gholizadeh, Davidson, Heydari, \& Salamonson, 2014). Korean people are less likely to seek a consultation from health professionals in terms of their psychological distress (Lee, Wachholtz, \& Choi, 2014). Therefore, considering this Korean cultural factor, it is recommended to perform a routine screening and cautious interventions for patients' psychosocial aspects in the recovery stages of MI. Future research should focus on exploring the impact of early HRQoL scores on patients' recovery from MI, future cardiac events and mortality. It may be interesting to know if HRQoL scores at the early stage of post-MI can predict HRQoL scores after a few months. Additionally, because of insufficient research, it also suggested HRQoL among MI patients who have a history of stroke should be studied in the future. 
A limitation of this study was that the descriptive and cross-sectional study design could not explain the causal relationships, although the stepwise regression was able to explain the percentage of variance and strength of the independent variables with the standardised coefficient values. Thus, more longitudinal or cohort studies may be required to develop better plans or transitional cares for recovery of HRQoL among patients with MI. Nevertheless, this study also has its own strengths. First, this research focused on HRQoL in the early phase of the patients with MI, which was inadequately investigated in previous literature. Studies on the acute stage of recovery from MI may be more useful for identifying patients who have more risk factors of impaired HRQoL. Second, considering the similarities between the current study and a previous study implemented in another city of Korea (Kim et al., 2015), it can be assumed that the study participants are representative of the Korean population.

\section{CONCLUSIONS}

The results of the study suggest that lower HRQoL was significantly associated with lower education level and poor perceived financial status, with having diabetes, a history of stroke and other heart diseases, and a higher level of depression, anxiety and stress. The findings of this study help to detect individual patients who possibly experience lower HRQoL after MI. While some factors are unlikely to be modified, early psychological and financial support may help reduce the impact of MI on patients' overall health and quality of life.

\section{Implications for clinical practice}

The results of the current study support the link between social determinants of health (education and financial status) and HRQoL. Patients admitted to hospital with MI should be monitored for symptoms of psychological distress. In addition, if necessary, timely counselling or psychological treatment should be provided to reduce the impact of physiological factors on patients' outcomes and recovery. 


\section{REFERENCES}

Anderson, L., \& Taylor, R. S. (2014). Cardiac rehabilitation for people with heart disease: an overview of Cochrane systematic reviews. International Journal Of Cardiology, 177(2), 348-361. doi:http://dx.doi.org/10.1016/j.ijcard.2014.10.011

Arnold, S. V., Masoudi, F. A., Rumsfeld, J. S., Li, Y., Jones, P. G., \& Spertus, J. A. (2013). Derivation and validation of a risk standardization model for benchmarking hospital performance for healthrelated quality of life outcomes after acute myocardial infarction. Circulation, 129(3), 313320. doi:https://doi.org/10.1161/CIRCULATIONAHA.113.001773

Benjamin, J. E., Muntner, S. P., Alonso, W. A., Bittencourt, P. M., Callaway, M. C., Carson, R. A., . . Virani, S. S. (2019). Heart Disease and Stroke Statistics-2019 Update: A Report From the American Heart Association. Circulation, 139(10), e56-e66. doi:10.1161/CIR.0000000000000659

Cha, E. (2014, Last updated Nov 10, 2014). Cha Korean translation of the DASS21. Retrieved from http://www2.psy.unsw.edu.au/dass/Korean/Korean\%20Cha.htm

Dixon, T., Lim, L. L.-Y., \& Oldridge, N. B. (2002). The MacNew heart disease health-related quality of life instrument: reference data for users. Quality of life Research, 11(2), 173-183. doi:10.1023/A:1015005109731

Feng, H.-P., Chien, W.-C., Cheng, W.-T., Chung, C.-H., Cheng, S.-M., \& Tzeng, W.-C. (2016). Risk of anxiety and depressive disorders in patients with myocardial infarction: A nationwide population-based cohort study. Medicine, 95(34), e4464-e4464. doi:10.1097/MD.0000000000004464

Ferrans, C. E., Zerwic, J. J., Wilbur, J. E., \& Larson, J. L. (2005). Conceptual model of health-related quality of life. Journal of Nursing Scholarship, 37(4), 336-342. doi:10.1111/j.15475069.2005.00058.x

Gholizadeh, L., Davidson, P. M., Heydari, M., \& Salamonson, Y. (2014). Heart Disease and Depression: Is Culture a Factor? Journal of Transcultural Nursing, 25(3), 290-295.

Guillemin, F., Bombardier, C., \& Beaton, D. (1993). Cross-cultural adaptation of health-related quality of life measures: literature review and proposed guidelines. Journal of clinical epidemiology, 46(12), 1417-1432. doi:http://dx.doi.org/10.1016/0895-4356(93)90142-N

Hawkes, A. L., Patrao, T. A., Ware, R., Atherton, J. J., Taylor, C. B., \& Oldenburg, B. F. (2013). Predictors of physical and mental health-related quality of life outcomes among myocardial infarction patients. BMC cardiovascular disorders, 13(1), 69. doi:https://doi.org/10.1186/1471-2261-13-69

Hong, I. (2011). Health related quality of life by smoking, drinking, exercise, obesity and sociodemographic variables using EQ-5D. Sahmyook University, Seoul, South Korea.

Hosseini, S. H., Ghaemian, A., Mehdizadeh, E., \& Ashraf, H. (2014). Contribution of depression and anxiety to impaired quality of life in survivors of myocardial infarction. International Journal Of Psychiatry In Clinical Practice, 18(3), 175-181. doi:10.3109/13651501.2014.940049

Kang, K., Gholizadeh, L., Han, H.-R., \& Inglis, S. C. (2018). Predictors of health-related quality of life in korean patients with myocardial infarction: a longitudinal observational study. Heart \& Lung, 47(2), 142-148. doi:10.1016/j.hrtlng.2017.12.005

Kang, K., Gholizadeh, L., Inglis, S. C., \& Han, H.-R. (2016). Interventions that improve health-related quality of life in patients with myocardial infarction. Quality of life Research, 25(11), 27252737. doi:https://doi.org/10.1007/s11136-016-1401-8

Kang, K., Gholizadeh, L., Inglis, S. C., \& Han, H.-R. (2017). Correlates of health-related quality of life in patients with myocardial infarction: A literature review. International Journal of Nursing Studies, 73, 1-16. doi:https://doi.org/10.1016/j.jnurstu.2017.04.010

Kang, K., Gholizadeh, L., Inglis, S. C., \& Han, H.-R. (2018). Validation of the Korean version of the MacNew heart disease health-related quality of life questionnaire. Journal of Nursing Research. 
Kim, H. M., Kim, J., \& Hwang, S. Y. (2015). Health-related quality of life in symptomatic postmyocardial infarction patients with left ventricular dysfunction. Asian Nursing Research, 9(1), 47-52. doi:http://dx.doi.org/10.1016/j.anr.2014.11.004

Lee, J., Wachholtz, A., \& Choi, K.-H. (2014). A review of the Korean cultural syndrome Hwa-Byung: suggestions for theory and intervention. Journal of Asia Pacific Counselling, 4(1), 49-64.

Lidell, E., Höfer, S., Saner, H., Perk, J., Hildingh, C., \& Oldridge, N. (2015). Health-related quality of life in European women following myocardial infarction: A cross-sectional study. European Journal of Cardiovascular Nursing, 14(4), 326-333. doi:doi: 10.1177/1474515114535330

Lovibond, S. H., Lovibond, P. F., \& Psychology Foundation of Australia. (1995). Manual for the Depression Anxiety Stress Scales (2nd ed.). Sydney, N.S.W: Psychology Foundation of Australia.

Oginska-Bulik, N. (2014). Type D personality and quality of life in subjects after myocardial infarction. Polish Heart Journal, 72(7), 624-630. doi:http://dx.doi.org/10.5603/KP.a2014.0066

Pallant, J. (2016). Multiple regression. In J. Pallant (Ed.), SPSS survival manual: a step by step guide to data analysis using IBM SPSS (6th ed., pp. 149-168). UK: McGraw-Hill Education.

Rafael, B., Simon, A., Drótos, G., \& Balog, P. (2014). Vital exhaustion and anxiety are related to subjective quality of life in patients with acute myocardial infarct before cardiac rehabilitation. Journal Of Clinical Nursing, 23(19-20), 2864-2873. doi:10.1111/jocn.12563

Schmidt, E. M., Szépligeti, T. S., Horváth-Puhó, T. E., Pedersen, T. L., Bøtker, T. H., \& Sørensen, T. H. (2016). Long-Term Survival Among Patients With Myocardial Infarction Before Age 50 Compared With the General Population: A Danish Nationwide Cohort Study. Circulation: Cardiovascular Quality and Outcomes, 9(5), 523-531. doi:10.1161/CIRCOUTCOMES.115.002661

Statistics Korea, Shin, H.-Y., Lee, J.-Y., Kim, J.-E., Lee, S., Youn, H., . . Huh, S. (2018). Cause-of-death statistics in 2016 in the Republic of Korea. Journal of the Korean Medical Association, 61(9), 573-584. doi:https://doi.org/10.5124/jkma.2018.61.9.573

Uchmanowicz, I., Loboz-Grudzien, K., Jankowska-Polanska, B., \& Sokalski, L. (2013). Influence of diabetes on health-related quality of life results in patients with acute coronary syndrome treated with coronary angioplasty. Acta Diabetologica, 50(2), 217-225. doi:http://dx.doi.org/10.1007/s00592-011-0280-2

Wang, W., Chow, A., Thompson, D. R., Koh, K., Kowitlawakul, Y., \& He, H.-G. (2016). Predictors of health-related quality of life among patients with myocardial infarction. Western Journal of Nursing Research, 38(1), 43-56. doi:10.1177/0193945914546201

Wang, W., Thompson, D. R., Ski, C. F., \& Liu, M. (2014). Health-related quality of life and its associated factors in Chinese myocardial infarction patients. European Journal Of Preventive Cardiology, 21(3), 321-329. doi:http://dx.doi.org/10.1177/2047487312454757

WHO. (2011). The determinants of health. Health Impact Assessment (HIA). Retrieved from http://www.who.int/hia/evidence/doh/en/

Wrzesniewski, K., \& Wlodarczyk, D. (2012). Sense of coherence as a personality predictor of the quality of life in men and women after myocardial infarction. Kardiologia Polska, 70(2), 157163. Retrieved from https://ojs.kardiologiapolska.pl/kp/article/view/221

Xu, M. X., Bao, E. H., Strait, W. K., Edmondson, F. D., Davidson, P. K., Beltrame, E. J., . . Krumholz, M. H. (2017). Perceived Stress After Acute Myocardial Infarction: A Comparison Between Young and Middle-Aged Women Versus Men. Psychosomatic Medicine, 79(1), 50-58. doi:10.1097/PSY.0000000000000429

Zimmerman, E., \& Woolf, S. H. (2014). Understanding the relationship between education and health. Institute of Medicine, Washington, DC. : National Academy of Sciences Retrieved from https://apha.confex.com/apha/142am/webprogram/Handout/Paper315693/Final\%20BPHUnderstandingTheRelationship.pdf 
Table 1. Preliminary Analyses of HRQoL Scores by Participants' Characteristics ( $n=150)$

\begin{tabular}{|c|c|c|c|c|c|c|}
\hline Demographic factors & & $\mathrm{n}$ & $\%$ & MacNew $(\text { Mean } \pm \text { SD })^{\dagger}$ & $t / \mathrm{F}$ & $p$ \\
\hline \multirow[t]{4}{*}{ Age (years) } & $<55$ & 30 & 20.0 & $4.82 \pm 0.87$ & \multirow[t]{4}{*}{5.824} & \multirow[t]{4}{*}{$.001 * *$} \\
\hline & $55-64$ & 43 & 28.7 & $4.58 \pm 0.78$ & & \\
\hline & $65-74$ & 43 & 28.7 & $4.41 \pm 0.74$ & & \\
\hline & $75 \leq$ & 34 & 22.6 & $4.03 \pm 0.82$ & & \\
\hline \multirow[t]{2}{*}{ Gender } & Female & 43 & 28.7 & $4.17 \pm 0.79$ & \multirow[t]{2}{*}{-2.678} & \multirow[t]{2}{*}{$.008 * *$} \\
\hline & Male & 107 & 71.3 & $4.57 \pm 0.83$ & & \\
\hline \multirow[t]{2}{*}{ Marital status } & Married & 129 & 86.0 & $4.54 \pm 0.80$ & \multirow[t]{2}{*}{3.163} & \multirow[t]{2}{*}{$.002 * *$} \\
\hline & $\begin{array}{l}\text { Never married/Separated/Divorced/ } \\
\text { Widowed }\end{array}$ & 21 & 14.0 & $3.94 \pm 0.88$ & & \\
\hline \multirow[t]{4}{*}{ Level of education } & Primary or less & 40 & 26.7 & $4.08 \pm 0.74$ & \multirow[t]{4}{*}{6.403} & \multirow[t]{4}{*}{$.000 * *$} \\
\hline & Middle school & 25 & 16.7 & $4.28 \pm 0.80$ & & \\
\hline & High school & 54 & 36.0 & $4.59 \pm 0.80$ & & \\
\hline & Undergraduate or more & 31 & 20.6 & $4.85 \pm 0.84$ & & \\
\hline \multirow[t]{2}{*}{ Employment status } & Employed & 60 & 40.0 & $4.75 \pm 0.72$ & \multirow[t]{2}{*}{3.648} & \multirow[t]{2}{*}{$.000 * *$} \\
\hline & $\begin{array}{l}\text { Unpaid family workers/Retired / } \\
\text { Unemployed }\end{array}$ & 90 & 60.0 & $4.26 \pm 0.85$ & & \\
\hline \multirow{2}{*}{$\begin{array}{l}\text { Financial status } \\
\text { (Subjective) }\end{array}$} & Excellent / Good & 21 & 14.0 & $5.11 \pm 0.85$ & \multirow[t]{2}{*}{4.110} & \multirow[t]{2}{*}{$.000 * *$} \\
\hline & Only fair / Poor & 129 & 86.0 & $4.35 \pm 0.78$ & & \\
\hline \multicolumn{7}{|l|}{ Behavioural factors } \\
\hline \multirow[t]{3}{*}{ Physical activity } & $\begin{array}{l}\text { At least } 30 \text { minutes moderate physical } \\
\text { activity most or all days of the week }\end{array}$ & 42 & 28.0 & $4.76 \pm 0.71$ & \multirow[t]{3}{*}{5.141} & \multirow[t]{3}{*}{$.007 * *$} \\
\hline & $\begin{array}{l}\text { Less } 30 \text { minutes moderate physical } \\
\text { activity less than } 5 \text { days in a week }\end{array}$ & 31 & 20.7 & $4.51 \pm 0.81$ & & \\
\hline & Not physically active & 77 & 51.3 & $4.27 \pm 0.86$ & & \\
\hline \multirow[t]{3}{*}{ Smoking } & Non-smoker & 85 & 56.7 & $4.31 \pm 0.86$ & \multirow[t]{3}{*}{3.531} & \multirow[t]{3}{*}{$.032 *$} \\
\hline & Previous smoker & 15 & 10.0 & $4.47 \pm 0.71$ & & \\
\hline & Current smoker & 50 & 33.3 & $4.70 \pm 0.77$ & & \\
\hline \multirow[t]{2}{*}{ Alcohol consumption } & No & 107 & 71.3 & $4.33 \pm 0.85$ & \multirow[t]{2}{*}{-2.983} & \multirow[t]{2}{*}{$.003 * *$} \\
\hline & Yes & 43 & 28.7 & $4.77 \pm 0.71$ & & \\
\hline
\end{tabular}




\begin{tabular}{|c|c|c|c|c|c|c|c|}
\hline \multirow[t]{2}{*}{ ST-elevation } & NSTEMI & & 89 & 59.3 & $4.37 \pm 0.83$ & \multirow[t]{2}{*}{-1.478} & \multirow[t]{2}{*}{.141} \\
\hline & STEMI & & 61 & 40.7 & $4.58 \pm 0.83$ & & \\
\hline \multirow{12}{*}{$\begin{array}{l}\text { Medical } \\
\text { Characteristics }\end{array}$} & Hypertension: & Yes & 75 & 50.0 & $4.27 \pm 0.84$ & \multirow[t]{2}{*}{-2.721} & \multirow[t]{2}{*}{$.007 * *$} \\
\hline & & No & 75 & 50.0 & $4.64 \pm 0.80$ & & \\
\hline & Diabetes: & Yes & 47 & 31.3 & $4.16 \pm 0.75$ & \multirow{2}{*}{-2.953} & \multirow{2}{*}{$.004 * *$} \\
\hline & & No & 103 & 68.7 & $4.59 \pm 0.84$ & & \\
\hline & Stroke: & Yes & 8 & 5.3 & $3.74 \pm 0.74$ & \multirow[t]{2}{*}{-2.551} & \multirow[t]{2}{*}{$.012 *$} \\
\hline & & No & 142 & 94.7 & $4.50 \pm 0.82$ & & \\
\hline & Other heart disease: & Yes & 25 & 16.7 & $4.02 \pm 0.81$ & \multirow[t]{2}{*}{-2.902} & \multirow[t]{2}{*}{$.004 * *$} \\
\hline & & No & 125 & 83.3 & $4.54 \pm 0.82$ & & \\
\hline & Previous MI: & Yes & 37 & 24.7 & $4.22 \pm 0.84$ & \multirow[t]{2}{*}{-2.019} & \multirow[t]{2}{*}{$.045^{*}$} \\
\hline & & No & 113 & 75.3 & $4.53 \pm 0.82$ & & \\
\hline & Other comorbidities: & Yes & 58 & 38.7 & $4.31 \pm 0.82$ & \multirow[t]{2}{*}{-1.675} & \multirow[t]{2}{*}{.096} \\
\hline & & No & 92 & 61.3 & $4.55 \pm 0.83$ & & \\
\hline Psychosocial fa & & & & & Total & \multicolumn{2}{|c|}{ Pearson correlation $\neq$} \\
\hline \multirow[t]{4}{*}{ DASS 21} & & & & & $17.05 \pm 9.26$ & \multicolumn{2}{|c|}{$-.520 * *$} \\
\hline & Depression & & & & $3.69 \pm 3.76$ & \multicolumn{2}{|c|}{$-.427 * *$} \\
\hline & Anxiety & & & & $5.23 \pm 3.09$ & \multicolumn{2}{|c|}{$-.485^{* *}$} \\
\hline & Stress & & & & $8.13 \pm 4.55$ & \multicolumn{2}{|c|}{$-.376 * *$} \\
\hline
\end{tabular}

DASS = Depression Anxiety and Stress Scale; HRQoL = Health-Related Quality of Life; MacNew = the MacNew Heart Disease Health-Related Quality of Life Questionnaire; NSTEMI = Non-ST Segment Elevation Myocardial Infarction; STEMI = ST Segment Elevation Myocardial Infarction

* Significant at the level of $p<.05$.

$* *$ Significant at the level of $p<.01$.

$\uparrow$ A range of mean scores of the MacNew: 1 7.

\$ Pearson correlation with the total MacNew score for each DASS 21 subscale. 
Table 2. Correlations between Independent Variables

\begin{tabular}{|c|c|c|c|c|c|c|c|c|c|c|c|c|c|c|c|c|c|}
\hline & Age & Gender & $\begin{array}{l}\text { Marital } \\
\text { status }\end{array}$ & $\begin{array}{c}\begin{array}{c}\text { Level of } \\
\text { educatio } \\
\mathrm{n}\end{array} \\
\end{array}$ & $\begin{array}{c}\text { Employ } \\
\text { ment }\end{array}$ & $\begin{array}{l}\text { Financial } \\
\text { status }\end{array}$ & Activity & Smoking & Alcohol & $\begin{array}{c}\text { ST- } \\
\text { elevation }\end{array}$ & $\begin{array}{l}\text { Hyperten } \\
\text { sion }\end{array}$ & Diabetes & Stroke & $\begin{array}{c}\text { Other } \\
\text { heart } \\
\text { disease } \\
\end{array}$ & $\begin{array}{l}\text { Previous } \\
\text { MI }\end{array}$ & $\begin{array}{c}\text { Other } \\
\text { comorbid } \\
\text { ities } \\
\end{array}$ & $\begin{array}{c}\text { DASS } \\
\text { total }\end{array}$ \\
\hline Age & 1 & & & & & & & & & & & & & & & & \\
\hline Gender & $-.404^{* *}$ & 1 & & & & & & & & & & & & & & & \\
\hline Marital status & $.177^{*}$ & $-.254^{* *}$ & 1 & & & & & & & & & & & & & & \\
\hline Level of education & $-.592^{* *}$ & $.469^{* *}$ & $-.240^{* *}$ & 1 & & & & & & & & & & & & & \\
\hline Employment & $.602^{* *}$ & $-.367^{* *}$ & .133 & $-.430^{* *}$ & 1 & & & & & & & & & & & & \\
\hline Financial status & $.244^{* *}$ & -.043 & .107 & $-.217^{* *}$ & $.220^{* *}$ & 1 & & & & & & & & & & & \\
\hline Activity & .067 & -.102 & .159 & $-.161^{*}$ & -.016 & .132 & 1 & & & & & & & & & & \\
\hline Smoking & $-.484^{* *}$ & $.464^{* *}$ & $-.232^{* *}$ & $.316^{* *}$ & $-.414^{* *}$ & .044 & .01 & 1 & & & & & & & & & \\
\hline Alcohol & $-.382^{* *}$ & $.304^{* * *}$ & -.128 & $.232^{* *}$ & $-.385^{* *}$ & $-.169^{*}$ & .051 & $.305^{* *}$ & 1 & & & & & & & & \\
\hline ST-elevation & -.129 & $.195^{*}$ & -.06 & .138 & .011 & .021 & -.067 & .092 & $.195^{*}$ & 1 & & & & & & & \\
\hline Hypertension & .159 & -.133 & .058 & -.11 & .082 & .058 & -.054 & $-.167^{*}$ & -.133 & -.149 & 1 & & & & & & \\
\hline Diabetes & $.173^{*}$ & -.144 & .017 & -.05 & $.199^{*}$ & .065 & .101 & -.047 & $-.174^{*}$ & -.062 & .158 & 1 & & & & & \\
\hline Stroke & .132 & -.046 & $.161^{*}$ & -.083 & $.194^{*}$ & .096 & -.03 & -.037 & -.15 & -.136 & .119 & -.096 & 1 & & & & \\
\hline $\begin{array}{l}\text { Other heart } \\
\text { disease }\end{array}$ & .145 & -.112 & .129 & -.06 & .073 & -.026 & .087 & -.159 & -.046 & -.115 & .125 & .006 & .053 & 1 & & & \\
\hline Previous MI & $.192^{*}$ & -.048 & $.215^{* *}$ & -.081 & $.246^{* *}$ & .142 & -.011 & $-.208^{*}$ & -.158 & $-.222^{* *}$ & $.170^{*}$ & .08 & .071 & $.367^{* * *}$ & 1 & & \\
\hline $\begin{array}{l}\text { Other } \\
\text { comorbidities }\end{array}$ & $.335^{* *}$ & -.102 & .035 & -.13 & $.173^{*}$ & .084 & .119 & $-.275^{* *}$ & $-.201^{*}$ & -.156 & .137 & .083 & .055 & $.233^{* * *}$ & $.181^{*}$ & 1 & \\
\hline DASS total & .04 & .013 & $.187^{*}$ & -.092 & .074 & $.177^{*}$ & .13 & -.036 & -.05 & -.022 & .084 & .037 & .069 & .046 & .159 & -.024 & 1 \\
\hline
\end{tabular}

DASS = Depression Anxiety and Stress Scale; MI = Myocardial Infarction.

**. Correlation is significant at the .01 level (2-tailed).

*. Correlation is significant at the .05 level (2-tailed) 
Table 3. Collinearity Test and Backward Elimination Stepwise Regression Analysis

\begin{tabular}{|c|c|c|c|c|c|c|c|c|c|c|c|c|c|c|c|c|c|}
\hline \multirow[b]{2}{*}{ Demographic factors } & \multicolumn{2}{|c|}{ Collinearity } & \multicolumn{3}{|c|}{ Step 1} & \multicolumn{3}{|c|}{ Step 2} & \multicolumn{3}{|c|}{ Step 3} & \multicolumn{3}{|c|}{ Step 4} & \multicolumn{3}{|c|}{ Step 5} \\
\hline & Tol. & VIF & $\beta$ & $t$-value & $p$ & $\beta$ & $t$-value & $p$ & $\beta$ & $t$-value & $p$ & $\beta$ & $t$-value & $p$ & $\beta$ & $t$-value & $p$ \\
\hline Age & 0.508 & 1.968 & $\begin{array}{c}-0.019 \\
\end{array}$ & -0.228 & .820 & - & - & - & - & - & - & - & - & - & - & - & - \\
\hline Gender & 0.606 & 1.650 & -0.007 & -0.092 & .926 & - & - & - & - & - & - & - & - & - & - & - & - \\
\hline Marriage & 0.809 & 1.237 & -0.035 & -0.528 & .598 & -0.030 & -0.465 & .643 & - & - & - & - & - & - & - & - & - \\
\hline Education level & 0.548 & 1.826 & 0.142 & 1.770 & .079 & 0.158 & 2.395 & $.018^{*}$ & 0.172 & 2.655 & $.009^{* *}$ & 0.213 & 3.454 & $.001 * *$ & 0.228 & 3.688 & $.000^{* *}$ \\
\hline Employment & 0.562 & 1.780 & -0.035 & -0.444 & .658 & - & - & - & - & - & - & - & - & - & - & - & - \\
\hline Financial status & 0.829 & 1.207 & -0.163 & -2.486 & $.014^{*}$ & -0.169 & -2.664 & $.009 * *$ & -0.169 & -2.716 & $.007^{* *}$ & -0.159 & -2.557 & $.012 *$ & -0.169 & -2.705 & $.008^{* *}$ \\
\hline \multicolumn{18}{|l|}{ Behavioural factors } \\
\hline Physical activity & 0.886 & 1.128 & -0.129 & -2.032 & $.044^{*}$ & -0.126 & -2.013 & $.046^{*}$ & -0.128 & -2.088 & $.039 *$ & -0.113 & -1.839 & .068 & - & - & - \\
\hline Smoking & 0.594 & 1.685 & 0.076 & 0.987 & .325 & 0.089 & 1.321 & .189 & 0.100 & 1.565 & .120 & - & - & - & - & - & - \\
\hline Alcohol consumption & 0.753 & 1.329 & 0.061 & 0.894 & .373 & 0.069 & 1.053 & .294 & - & - & - & - & - & - & - & - & - \\
\hline \multicolumn{18}{|l|}{ Disease-related factors } \\
\hline Hypertension & 0.891 & 1.123 & -0.086 & -1.368 & .174 & -0.083 & -1.336 & .184 & -0.078 & -1.262 & .209 & - & - & - & - & - & - \\
\hline Diabetes & 0.862 & 1.160 & -0.170 & -2.648 & $.009 * *$ & -0.177 & -2.870 & $.005^{* *}$ & -0.184 & -3.034 & $.003^{* *}$ & -0.201 & -3.348 & $.001 * *$ & -0.210 & -3.480 & $.001^{* *}$ \\
\hline Stroke & 0.888 & 1.126 & -0.128 & -2.032 & $.044^{*}$ & -0.135 & -2.189 & $.030^{*}$ & -0.146 & -2.415 & $.017 *$ & -0.155 & -2.573 & $.011^{*}$ & -0.150 & -2.458 & $.015^{*}$ \\
\hline Other heart disease & 0.828 & 1.208 & -0.187 & -2.859 & $.005 * *$ & -0.187 & -2.890 & $.004 * *$ & -0.161 & -2.666 & $.009 * *$ & -0.184 & -3.074 & $.003^{* *}$ & -0.193 & -3.207 & $.002 * *$ \\
\hline Previous MI & 0.742 & 1.348 & 0.089 & 1.283 & .202 & 0.082 & 1.223 & .224 & - & - & - & - & - & - & - & - & - \\
\hline \multicolumn{18}{|l|}{ Psychosocial factors } \\
\hline \multirow[t]{3}{*}{ DASS total } & 0.905 & 1.105 & -0.429 & -6.842 & $.000 * *$ & -0.428 & -6.950 & $.000^{* *}$ & -0.423 & -6.985 & $.000^{* * *}$ & -0.431 & -7.064 & $.000 * *$ & -0.442 & -7.224 & $.000 * *$ \\
\hline & & & \multicolumn{3}{|c|}{$R^{2}=0.524$, adjusted $R^{2}=0.471$} & \multirow{2}{*}{\multicolumn{3}{|c|}{$\begin{array}{l}R^{2}=0.523, \text { adjusted } R^{2}=0.481 \\
F=12.525(n=000)\end{array}$}} & \multirow{2}{*}{\multicolumn{3}{|c|}{$\begin{array}{l}R^{2}=0.514, \text { adjusted } R^{2}=0.483 \\
F=16.464(p=.000)\end{array}$}} & \multirow{2}{*}{\multicolumn{3}{|c|}{$\begin{array}{l}R^{2}=0.498, \text { adjusted } R^{2}=0.474 \\
F=20.151(p=.000)\end{array}$}} & \multirow{2}{*}{\multicolumn{3}{|c|}{$\begin{array}{l}R^{2}=0.486, \text { adjusted } R^{2}=0.465 \\
F=22.570(p=.000)\end{array}$}} \\
\hline & & & $F=9.8$ & $p=.000)$ & & & & & & & & & & & & & \\
\hline
\end{tabular}

$\beta=$ Standardised $\beta$; DASS $=$ Depression Anxiety and Stress Scale; MacNew $=$ the MacNew Heart Disease Health-Related Quality of Life Questionnaire; Tol = Tolerance; VIF $=$ Variance Inflation Factor.

* Significant at the level of $p<.05$

**Significant at the level of $p<.0$ 